\title{
Progress in Forward Osmosis Membrane Separation Process
}

\author{
Qiaozhen Chen, Wenxuan Xu, and Qingchun Ge* \\ College of Environment and Resources, Fuzhou University, Fuzhou, Fujian 350116, China
}

\begin{abstract}
Forward osmosis (FO) has been extensively investigated and demonstrated its advantages in a range of FO applications over the past decade. However, challenges still remain in terms of the lack of both efficient FO membranes and appropriate draw solutes for practical FO applications. To promote the advancement of FO technology, considerable efforts have been made in exploring novel FO membranes and draw solutes in recent years. This paper will provide a short review on the progress of both FO membranes and draw solutes. First of all, a brief overview on FO principle is given. Then the progress in FO technology related to FO membrane and draw solute is presented with specific examples. Finally, challenges and future directions of FO technology in exploring efficient FO membranes and promising draw solutes are also highlighted. This article may provide new insights into the future development of FO technology and promote practical FO applications.
\end{abstract}

Keywords forward osmosis, draw solution, forward osmosis membrane, forward osmosis application

\section{Introduction}

Freshwater shortage has been becoming a more and more severe problem globally. ${ }^{[1-4]}$ To mitigate this problem, various technologies for clean water production have been explored worldwide recently. ${ }^{[5-9]}$ Membrane technology has shown a great potential in water treatment in view of the advantages of no phase change, strong adaptability, relatively simple operation and low cost. ${ }^{[5,10-12]}$ A range of pressure-driven membrane processes, such as microfiltration (MF), ${ }^{[13-16]}$ ultrafiltration (UF), ${ }^{[13,17,18]}$ nanofiltration (NF), ${ }^{[19-21]}$ and reverse osmosis (RO) $)^{[22-26]}$ have been extensively used for clean water production through either wastewater reuse or brackish water/ seawater desalination. However, some issues, such as severe membrane fouling, low water recovery rate, intensive-energy consumption and relatively low quality of product water, occur frequently during these processes. $^{[10,13,17,23,27]}$

FO has been recognized as a promising membrane process because of the following characteristics: (1) no requirement of hydraulic pressure; (2) a relatively high water recovery rate; (3) low membrane fouling propensity due to the absence of hydraulic pressure; (4) environmental friendliness. Given these merits, FO technology has been applied to a wide range of fields, such as seawater/brackish water desalination, ${ }^{[4,24,28]}$ wastewater treatment, ${ }^{[8,29-31]}$ and many other areas. ${ }^{[32-36]}$ Although FO exhibits a great potential in alleviating the issues caused by freshwater shortage, challenges, such as relatively low water permeability, high reverse solute diffusion, severe concentration polarization (CP), and membrane fouling, are still present in FO applications. ${ }^{[37-39]}$ To eliminate these problems, exploration of appropriate semi-permeable FO membrane and draw solute is urgently needed. Great efforts have been made in the development of FO technology in recent years, and a wide range of powerful FO membranes and suitable draw solutes have been proposed to date.

The objectives of this paper are to review the recent development of FO membranes and draw solutes briefly, and propose perspectives on future directions in exploring highly selective FO membranes and ideal draw solutes.

\section{FO principle}

A representative diagram of an FO process coupled with a post-treatment process is shown in Figure 1.

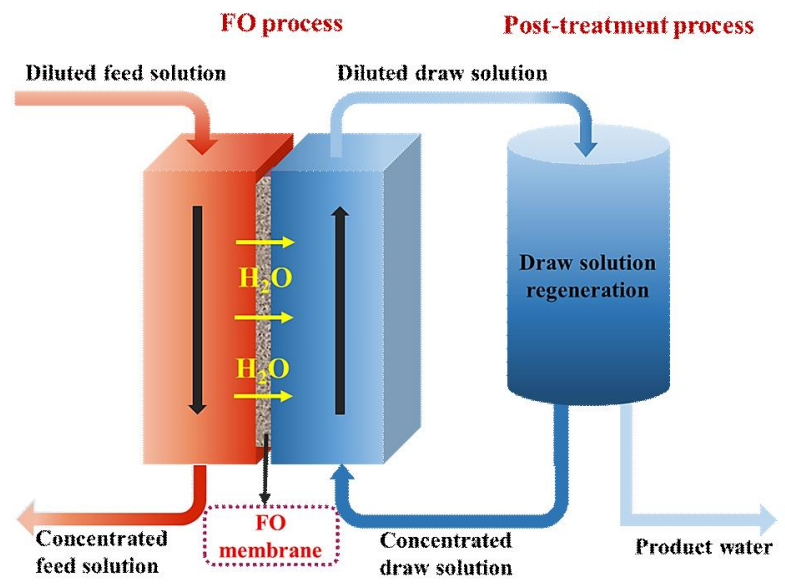

Figure 1 A representative diagram of an FO process coupled with a post-treatment process.

In an FO process, water from the feed side permeates to the draw solution side driven by the osmotic pressure difference across a semi-permeable FO membrane. As a result, a concentrated feed solution and a dilute draw solution are obtained after an FO process. Clearly, product water cannot be obtained directly from a single FO process. A post-treatment process which can separate the product water from the dilute draw solution is usually required after the FO process. Therefore, it is critical to explore an appropriate draw solute

* E-mail: qcge2015@fzu.edu.cn; Tel.: 0086-0591-22866219

Received August 6, 2017; accepted August 25, 2017.

Supporting information for this article is available on the WWW under www.genchemistry.org. 
with satisfactory FO performance and being readily separated from water. Meanwhile, a semi-permeable FO membrane with high selectivity is also crucial for an FO process. FO membrane and draw solute are the key factors determining both FO performance and the subsequent post-treatment.

\section{FO membrane}

As an FO membrane is one of the two crucial elements in FO, its properties determine the FO performance and applications. ${ }^{[40,41]}$ An FO membrane usually consists of a dense selective layer and a porous support layer. Generally, the former is able to reject the solutes in both feed and draw solutions while the latter provides mechanical support in an FO process. ${ }^{[42]}$ Two operation modes are usually used according to the membrane orientation, viz. pressure retarded osmosis (PRO) mode where the active layer faces a draw solution, and FO mode in which the support layer faces a draw solution. ${ }^{[39]}$ Parameters of water flux $\left(J_{\mathrm{w}}\right)$ and reverse solute flux $\left(J_{\mathrm{s}}\right)$ are usually used to evaluate the FO performance. Theoretically, $J_{\mathrm{w}}\left(\mathrm{L} \cdot \mathrm{m}^{-2} \cdot \mathrm{h}^{-1}\right.$, abbreviated as $\mathrm{LMH}$ ) in an $\mathrm{FO}$ process can be described by the following equation: ${ }^{[40]}$

$$
J_{w}=A \cdot \sigma \cdot \Delta \pi
$$

where $A$ is the water permeability coefficient, $\sigma$ is the reflection coefficient and $\Delta \pi$ is the osmotic pressure difference across an FO membrane. The effective $\Delta \pi\left(\Delta \pi_{\text {eff }}\right)$ is usually lower than the theoretical one due to the presence of $\mathrm{CP}$ phenomenon in FO. Therefore, a much lower $J_{\mathrm{w}}$ is obtained in practice. CP exists in membrane separation processes and causes a water flux decline. $\mathrm{CP}$ is closely related to membrane structure parameter $(S)$ that was defined as the follow: ${ }^{[38]}$

$$
S=\frac{t_{s} \tau}{\varepsilon}
$$

where $t_{\mathrm{s}}$ is the thickness of the support layer, $\tau$ is the tortuosity and $\varepsilon$ is the porosity. Generally, the membrane with a small $S$ value, namely, thin support layer, low tortuosity and high porosity, implies low $\mathrm{CP}$ tendency which is beneficial for membrane performance.

Membrane fouling is another phenomenon in FO processes detrimentally affecting FO performance. ${ }^{[35,37]}$ Membrane fouling leads to a water flux decline as a result of the increase of water transport resistance when solutes attach on membrane surface or diffuse into membrane interior ${ }^{[39,43]}$ Properties of membrane surface, such as hydrophilicity, charged state, roughness and structure, are closely related to the membrane fouling formation.

As most FO membranes are not perfectly semi-permeable, draw or feed solutes may diffuse to the opposite side during an FO process. ${ }^{[39]}$ The reverse draw solute flux, $J_{\mathrm{s}}\left(\mathrm{g} \cdot \mathrm{m}^{-2} \cdot \mathrm{h}^{-1}\right.$, abbreviated as $\mathrm{gMH})$, can be obtained from the following equation: ${ }^{[40]}$

$$
J_{\mathrm{s}}=\frac{C_{t} V_{t}-C_{0} V_{0}}{A \cdot \Delta t}
$$

where $C_{\mathrm{t}}(\mathrm{g} / \mathrm{L})$ and $V_{\mathrm{t}}(\mathrm{L})$ are the salt concentration in feed and feed volume over a predetermined time $\Delta t(\mathrm{~h})$, respectively, while $C_{0}(\mathrm{~g} / \mathrm{L})$ and $V_{0}(\mathrm{~L})$ are the initial salt concentration and feed volume, respectively, during the test. $A\left(\mathrm{~m}^{2}\right)$ is the effective membrane area.

To improve FO performance, an FO membrane with the following characteristics is highly desirable: ${ }^{[38,44]}$ (1) high water flux and low reverse solute diffusion; (2) minimal $\mathrm{CP}$ effect and membrane fouling; (3) high mechanical strength and good chemical stability. FO membranes with such characteristics are the directions for novel FO membrane exploration.

\section{Draw solution}

As the osmotic pressure difference across an FO membrane is the driving force in $\mathrm{FO}$, draw solution usually determines the magnitude of the osmotic pressure difference and hence plays a crucial role in the FO process. The osmotic pressure $(\pi)$ of a dilute solution can be expressed using the Van't Hoff equation: ${ }^{[45]}$

$$
\pi=i M R T
$$

where $\pi$ is the osmotic pressure (atm), $i$ is the Van't Hoff factor, M is the solute molar concentration $\left(\mathrm{mol} \cdot \mathrm{L}^{-1}\right), R$ is the universal gas constant $\left(0.08314 \mathrm{~L} \cdot \mathrm{bar} \cdot \mathrm{mol}^{-1} \cdot \mathrm{K}^{-1}\right)$, and $T$ is the absolute temperature (K).

The real osmotic pressure of a solution associates with the ionic or molecular numbers in the solution. An ideal draw solution should fulfill the following requirements: (1) good water solubility, high dissociation degree and capability to produce high osmotic pressure; (2) a reasonable molecular size to ensure a minimal reverse solute diffusion in FO; (3) a lowest possible viscosity in order not to cause a high diffusion coefficient and severe internal CP (ICP) phenomenon; (4) easy separation from water; (5) other criteria, such as zero toxicity, compatible with the FO membrane, and etc.

\section{Progress in FO research}

Novel FO membrane and draw solute with good FO performance are both the research focus of FO technology. Considerable efforts have been made in exploring FO membrane and draw solute. ${ }^{[39]}$ With the advancement of material science, a wide range of novel FO membranes and draw solutes have been proposed over the past decade ${ }^{[11,46]}$ The development of FO membrane and draw solute will be discussed in the following sections.

\section{Advances in $\mathrm{FO}$ membranes}

The development of FO membrane is closely related to the progress of material science. Initially RO membranes were applied to FO processes. ${ }^{[47,48]}$ However, much lower fluxes than theoretical value were obtained due to the high transport resistance as a result of the high thickness of RO membranes. There were few structurally designed membranes particularly for FO applications until the first commercial cellulose triacetate (CTA) flat sleet membrane was developed by Hydration Technologies Inc. (HTI) in the 1990 s. $^{[10,28]}$ Compared to RO membrane, FO membrane has a much thinner support layer and low structural parameter $S$ which contribute to lowering the inverse effect of ICP on FO water flux. Later in 2007, polybenzimidazole (PBI) NF hollow fiber membrane designed specifically for FO applications was developed by Wang et al. ${ }^{[49]}$ This PBI membrane may become a promising candidate for $\mathrm{FO}$ due to the desirable characteristics of PBI material, such as its self-charged properties, robust mechanical strength and excellent chemical stability. However, the low water permeability and rejection to monovalent ions hinder the PBI membrane from wide FO applications. In recent years, a large number of dual layer polysulfone/polyethersulfone-thin film composite (PSf/PES-TFC) FO membranes with a polyamide (PA) active layer have been proposed for FO ${ }^{[4,50,51]}$ Due to the thin and dense properties of the PA layer, the PSf/PES-TFC FO membranes exhibit good water permeability and high solute rejection which are superior to many other conventional FO membranes. However, there are still some problems in both the fabrication and applications of TFC PA membranes. For example, PA coating layer may not uniformly cover the porous support layer as a result of the incomplete interfacial polymerization reaction, or fall off in a long-term FO process due to the weak interaction between the two layers. ${ }^{[52]} \mathrm{Re}-$ cently, membrane modification has been proven to be effective in obtaining performance-improved FO membranes. Both physical and chemical methods have been adopted in membrane modifications. ${ }^{[39,52,53]}$ Physical modifications are usually carried out by adding hydrophilic materials, such as $\mathrm{TiO}_{2}, \mathrm{SiO}_{2}$, zeolite nanoparticles, etc. into either membrane substrates ${ }^{[54]}$ or membrane surfaces ${ }^{[55,56]}$ to improve the membrane performance. However, the added materials 
may leak out after a long-term operation as a result of no affinitive interaction between the added materials and membrane. Unlike physical modification, chemical modification is conducted on either membrane surface ${ }^{[57-60]}$ or membrane polymer prior to the membrane fabrication ${ }^{[61-65]}$ via chemical reactions between materials to enhance membrane hydrophilicity. Chemical modification on membrane or functionalization on membrane polymers (eg. sulfonation PES and PPSU, carboxylation PSf, etc.) can remarkably alter the membrane properties so that it can effectively reduce reverse solute diffusion and membrane fouling as well as water flux decline. Therefore, chemical modification on membrane has been becoming an effective way in obtaining competitive FO membranes. ${ }^{[1,52]}$

\section{Advances in draw solutes}

A large number of compounds have been explored as draw solutes for various FO applications over the past few decades. ${ }^{[40,46,66-68]}$ Commercial compounds of gases, nutrient substances, inorganic and organic salts have been widely investigated as draw solutes for FO before 2007. The development of draw solutes from commercial source has been reported in the literature. ${ }^{[40,66]}$ Although some of the commercial draw solutes exhibit good FO performance, problems, such as low water permeability, severe reverse solute diffusion and intensive energy consumption in recovery, are still widely present. ${ }^{[28,40,69,70]}$

To overcome these problems, synthetic draw solutes have been extensively investigated as draw solutes recently. ${ }^{[46,67,68]} \mathrm{Ge}$ and her coworkers $^{[71-73]}$ have conducted considerable studies on the design and synthesis of novel draw solutes. Some typically synthetic draw solutes will be specifically discussed as follows.

\section{Magnetic nanoparticles as draw solutes}

Generally, material of magnetic nanoparticles (MNPs) consists of a magnetic core and organic ligands. The former is magnetic sensitive which makes MNPs able to be separated from water when exposed to an external magnetic field, while the latter which usually carries a large number of hydrophilic groups is the source of osmotic pressure generation. MNPs can be designed freely based on the vast options of organic ligands according to the applications. As such, MNPs are able to not only produce high osmotic pressure and hence good water permeability in FO, but also be readily recovered by applying a magnetic field in post-treatment processes. These characteristics make MNPs competitive candidates to be draw solutes for FO.

MNPs are usually synthesized via a simple one-pot reaction through either thermal decomposition ${ }^{[71]}$ or coprecipitation. ${ }^{[74,75]}$ The synthesis schemes of MNPs via thermal decomposition and coprecipitaion together with some typically structures of MNPs are illustrated in Figures 2 and 3, respectively.

A series of poly (ethylene glycol) diacid [PEG-(COOH $\left.)_{2}\right]$ coated MNPs with different sizes have been synthesized by thermal decomposition. ${ }^{[71]}$ The size of PEG- $(\mathrm{COOH})_{2}$ MNPs ranges from 4.2 to 13.5 $\mathrm{nm}$. The feasibility of using PEG-(COOH$)_{2}$ MNPs as draw solutes for FO processes was systematically investigated in this study. ${ }^{[71]}$ The connection of PEG-(COOH $)_{2}$ to the nanoparticle surface is confirmed by FTIR spectroscopy (Figure S1). The magneticbehavior of PEG-(COOH $)_{2}$ MNPs is illustrated in Figure S2. A water flux of 13.5 LMH was obtained when PEG-(COOH $)_{2}$ MNPs with a mean particle size of $11.7 \mathrm{~nm}$ was employed as the draw solution and deionized (DI) water as the feed against a HTI flat sheet membrane under the PRO mode. The PEG-(COOH $)_{2}$ MNPs can be easily recovered by applying a magnetic separator to the dilute solution of PEG- $(\mathrm{COOH})_{2}$ MNPs after FO. The recovered PEG- $(\mathrm{COOH})_{2}$ MNPs were reused as draw solutes to new rounds of FO processes. However, the water flux decreased as much as $21 \%$ after nine runs of $\mathrm{FO}$ operation due to the particle aggregation occurred during the (PEG-(COOH $\left.)_{2}\right)$ MNPs (a)

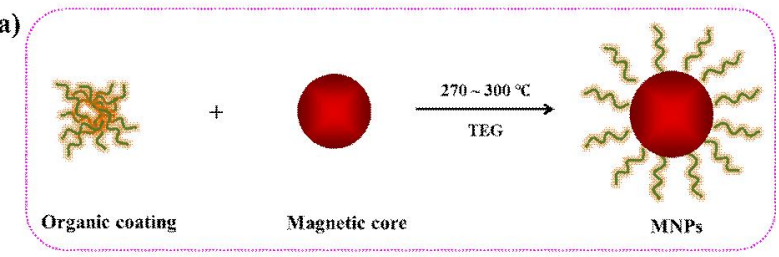

(b)

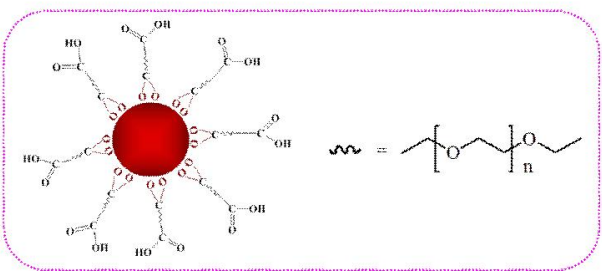

Figure 2 (a) Synthesis scheme of MNPs via thermal decomposition, (b) the structure of PEG-(COOH $)_{2}$ coated MNPs.

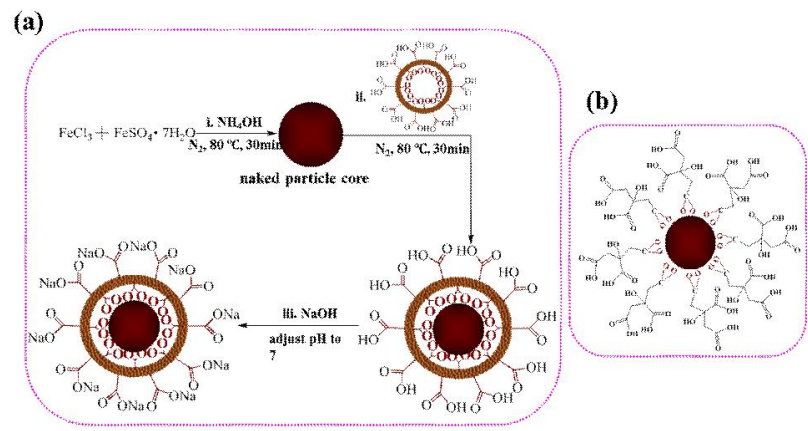

Figure 3 (a) Synthesis scheme of MNPs via coprecipitation, (b) the structure of CA coated MNPs.

recycling. The agglomeration phenomenon of MNPs under magnetic fields has been widely reported in the literature. ${ }^{[71,76]}$ To mitigate the aggregation problem of MNPs in recovery via a magnetic field, alternative recycling methods, such as UF, NF, were also proposed to regenerate MNPs. ${ }^{[75,77]}$

To synthesize hydrophilic MNPs under mild conditions, MNPs coated with hydroacids of oxalic acid (OA), citric acid (CA) and ethylenediaminetetraacetic acid (EDTA) were prepared via coprecipitation in a one-pot reaction (Figure 3) ${ }^{[75]}$ The structures of OA, and EDTA coated MNPs are illustrated in Figure S3. The coordination of the hydroacids to the nanoparticle surface is further confirmed by FTIR spectroscopy (Figure S4). The magnetic behavior of hydroacid coated MNPs is illustrated in Figure S5. OA, CA and EDTA all have good solubility in water and possess carboxyl functional groups. OA-, CA- and EDTA-coated MNPs carry a large number of carboxyl anions after neutralization with dilute $\mathrm{NaOH}$ which ensure them to produce high osmotic pressures when used as draw solutes. ${ }^{[75]}$ Among them, CA-coated MNPs exhibit the best FO performance in seawater desalination. A water flux of 8.5 LMH was achieved when $0.6 \mathrm{~g} / \mathrm{mL} \mathrm{CA}$ coated MNPs solution was used as the draw solution and $3.5 \mathrm{wt} \% \mathrm{NaCl}$ as the feed solution against a home-made TFC-PES hollow fiber membrane. ${ }^{[50]}$ The water recovery rate is much higher than those of MNPs draw solutes in FO seawater desalination. ${ }^{[7]}$ Meanwhile, negligible reverse solute fluxes were observed in the FO process and high recover efficiency in the post-treatment process via a hybrid system of magnetic field and NF membrane separation was achieved.

According to the aforementioned studies, MNPs can be used as 
draw solutes for FO in view of a positive water flux and a negligible reverse solute flux in the FO process. However, problems of particle aggregation during regeneration processes via a magnetic field and relatively low water flux than that generated by inorganic draw solutes are widely present. Solutions to these issues need to be provided for future development of MNPs draw solutes.

\section{Polyelectrolytes as draw solutes}

Electrolytes, such as inorganic and organic salts, ${ }^{[69,70,78]}$ have been widely used as draw solutes for FO because of their good water solubility and ionization ability. Regardless of high water permeability, however, draw solutes made from small electrolytes usually have severe reverse solute diffusion in FO processes. In view of this, Ge et $a l{ }^{[72]}$ synthesized a series of polyelectrolytes of polyacrylic acid sodium salts (PAA-Na) from PAA with different molecular weights for the FO process. The configurations of PAA and PAA-Na in their aqueous solutions are illustrated in Figure 4. Compared to PAA, the PAA-Na salts have higher water solubility, better ionizable ability and expanded structural configuration in water. These features make PAA-Na more attractive as draw solutes for the FO process. The suitability of PAA-Na as draw solutes was evaluated systematically via both commercial HTI flat sheet membrane and home-made cellulose acetate hollow fiber membrane in this study. A water flux of around 7.0 LMH was achieved when model seawater $(3.5 \mathrm{wt} \% \mathrm{NaCl})$ employed as the feed solution via the home-made cellulose acetate hollow fiber membrane. The dilute PAA-Na draw solution after FO can be efficiently concentrated via an UF process and reused to the FO process. Compared to those conventional inorganic draw solutes, such as $\mathrm{NaCl},{ }^{[70]} \mathrm{MgCl}_{2},{ }^{[69]}$ the polyelectrolytes of PAA-Na exhibit comparable water fluxes but much lower reverse solute diffusion in FO. Considering the superiority of PAA-Na as draw solutes, they were used for acid dye wastewater treatment via an forward osmosis-membrane distillation (FO-MD) hybrid system. ${ }^{[79]}$ In the FO-MD hybrid process, PAA-Na polyelectrolytes served as the draw solutes in the FO process to dehydrate the dye wastewater, meanwhile, the dilute PAA-Na solutions after FO were simultaneously concentrated through the MD process. With the integration of FO and MD, a continuous dye wastewater treatment process was established. The PAA-Na draw solutes are efficient in dye wastewater treatment with the feed solution concentrated from $50.0 \mathrm{ppm}$ to $81.9 \mathrm{ppm}$ after a $2-\mathrm{h}$ FO process under the $\mathrm{PRO}$ mode at $50{ }^{\circ} \mathrm{C}$ via cellulose acetate hollow fiber membranes.

(a)

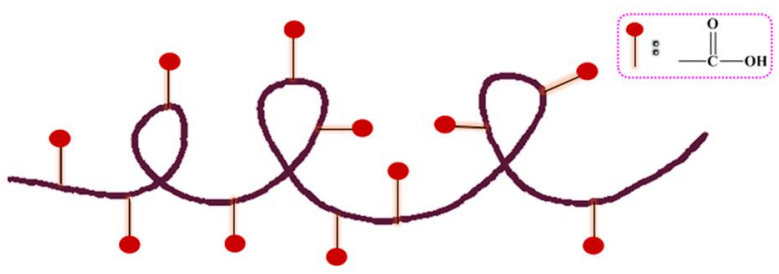

(b)

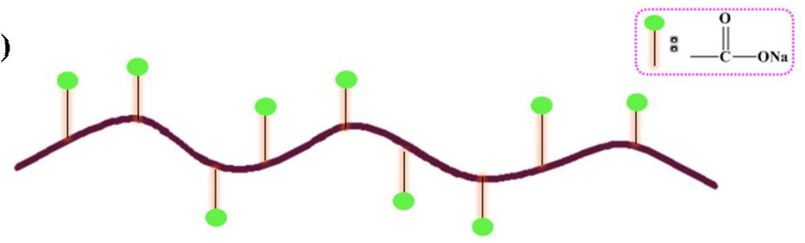

Figure 4 The configurations of: (a) PAA, and (b) PAA-Na in their respective aqueous solutions.

Generally, polyelectrolytes are more suitable than MNPs as draw solutes because of the much higher water recovery rate in FO and no aggregation problem in the post-treatment process. Meanwhile, polyelectrolytes are superior to small inorganic salts as draw solutes in terms of the much lower reverse solute fluxes in FO. However, the FO performance of polyelectrolytes degrades significantly with their concentration enhancement due to the remarkably increased viscosity and ICP adverse effect on FO performance.

\section{Hydroacid complexes as draw solutes}

Hydroacid complexes are another category of draw solutes proposed recently and have proven to be appropriate as draw solutes for FO processes. ${ }^{[31,32,73,80,81]}$ Hydroacid complexes are usually synthesized via a one-pot reaction under mild conditions which avoids not only the high reaction temperature required in synthesizing MNPs, ${ }^{[71,75]}$ but also the complicated synthesis procedures commonly confronted with other synthetic draw solutes. ${ }^{[82,83]}$ Hydroacid complexes usually consist of one or more transition metal core(s) and hydroacid ligands, which can be designed freely according to the application purpose by varying either metals or ligands. Such compounds have usually a tetrahedral or octahedral structure in the metal center, and thus possess an expanded molecular structure and have good thermal stability which not only conduce to a minimal reverse solutes flux in FO but also enable them to be recycled via either $\mathrm{NF}^{[32,73,80]}$ or $\mathrm{MD}^{[31,81,84]}$ processes in the post-treatment. The hydroacid ligands in a hydroacid complex generally carry a large number of hydrophilic carboxylic groups which are the sources of osmotic pressure generation. Such characteristics make hydroacid complexes suitable to be draw solutes for FO applications. Structures with a tetrahedral or octahedral configuration and representative hydroacid complexes, tetrahedral cupper-citric acid sodium salt ( $\mathrm{Na}-\mathrm{Cu}-\mathrm{CA})$ and octahedral chromium-oxalic acid sodium salt (Na-Cr-OA) are illustrated in Figure 5.

(a)

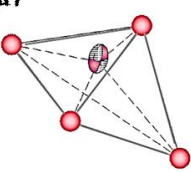

Tetrahedral configuration of a metal center

(b)

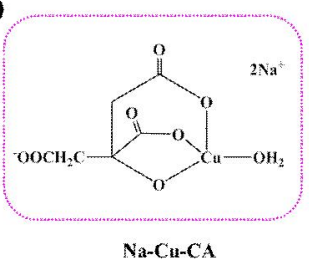

(c)

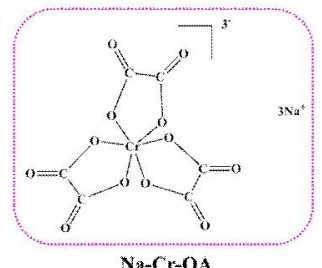

Figure 5 (a) The tetrahedral or octahedral structure of a metal center, (b) molecular structure of $\mathrm{Na}-\mathrm{Cu}-\mathrm{CA},(\mathrm{c})$ molecular structure of Na-Cr-OA.

The feasibility of using hydroacid complexes as a new class of draw solutes was firstly explored by Ge et al. in 2013. ${ }^{[73]}$ In their study, a series of hydroacid complexes which contain either a cupric or ferric core and hydroacid ligands of either CA, or malic acid (MA) or tartaric acid (TA) were synthesized. The proposed molecular structures of cupric and ferric complexes with hydroacid ligands are illustrated in Figure S6. The coordination of the acids to the $\mathrm{Cu}^{2+}$ or $\mathrm{Fe}^{3+}$ metal core was confirmed by FTIR spectroscopy (Figure S7). TGA measurements disclose the composition of the hydroacid com- 
plexes (Figure S8). The FO performance of hydroacid complex draw solutions was systematically tested by varying the experimental conditions against both commercial HTI membrane and home-made cellulose acetate membrane. ${ }^{[85]}$ The sodium salt of ferric CA complex of $\mathrm{Na}_{5}\left[\mathrm{Fe}\left(\mathrm{C}_{6} \mathrm{H}_{4} \mathrm{O}_{7}\right)_{2}\right](\mathrm{Na}-\mathrm{Fe}-\mathrm{CA})$ exhibits the best FO performance with a water flux of around 43.0 LMH and a negligible reverse solute flux when $2.0 \mathrm{M} \mathrm{Na}-\mathrm{Fe}-\mathrm{CA}$ solution as the draw solution and DI water as the feed via the cellulose acetate membrane under the PRO mode. The hydroacid complexes can be readily regenerated from their dilute solutions via a pressure-driven NF process due to the expanded structure in the metal center and a high solute rejection of above $90 \%$ can be achieved. To investigate the factors influencing the FO performance of hydroacid complex draw solutes, cobaltous $\mathrm{CA}$ sodium salts of $\mathrm{Na}_{4}\left[\mathrm{Co}\left(\mathrm{C}_{6} \mathrm{H}_{5} \mathrm{O}_{7}\right)_{2}\right]$ (Na-Co-CA) and $\mathrm{Na}_{2}\left[\mathrm{Co}_{2}-\right.$ $\left.\left(\mathrm{C}_{6} \mathrm{H}_{5} \mathrm{O}_{7}\right)_{2}\left(\mathrm{H}_{2} \mathrm{O}\right)_{4}\right]\left(\mathrm{Na}-\mathrm{CO}_{2}-\mathrm{CA}\right)$ were investigated as draw solutes and compared with Na-Fe-CA. ${ }^{[80]}$ The structures of Na-Co-CA and $\mathrm{Na}-\mathrm{CO}_{2}-\mathrm{CA}$ were illustrated in Figure S9. The coordination of CA to the cobalt or ferric metal core was confirmed by FTIR spectroscopy (Figure S10). Furthermore, the spectra of TGA measurements disclose the composition of the hydroacid complexes (Figure S11). Osmotic pressures of as high as $\sim 105 \mathrm{~atm}$ and $\sim 85 \mathrm{~atm}$ were produced by $2.0 \mathrm{M} \mathrm{Na-Fe-CA}$ and Na-Co-CA solutions, respectively. Meanwhile, the solutions of these complexes have much lower viscosity compared with those of PAA-Na series at their highest studied concentrations, ${ }^{[72]}$ indicative of higher diffusion coefficient of hydroacid complexes and hence lower ICP during FO processes. Accordingly, a high water flux of around 50.0 LMH and negligible reverse flux were achieved by a $2.0 \mathrm{M}$ Na-Fe-CA draw solution when DI water as the feed solution against a TFC-PES membrane. ${ }^{[50]} \mathrm{Na}-\mathrm{Fe}-\mathrm{CA}$ is proven to be more powerful as a draw solute than its analogues of $\mathrm{Na}-\mathrm{Co}-\mathrm{CA}$ and $\mathrm{Na}-\mathrm{Co} 2-\mathrm{CA}$. Later, two draw solutes of ferric and chromic oxalic acid complexes in the forms of sodium salts, denoted as $\mathrm{Na}-\mathrm{Fe}-\mathrm{OA}$ and $\mathrm{Na}-\mathrm{Cr}-\mathrm{OA}$ respectively, were synthesized and applied to the FO process. ${ }^{[32]}$ The X-ray single crystal structures of anionic Na-Fe-OA and $\mathrm{Na}-\mathrm{Cr}-\mathrm{OA}$ were illustrated in Figure S13. The coordination of the $\mathrm{OA}$ to the $\mathrm{Cr}^{3+}$ or $\mathrm{Fe}^{3+}$ metal core was confirmed by FTIR spectroscopy (Figure S14). Na-Cr-OA can produce a higher osmotic pressure than $\mathrm{Na}-\mathrm{Fe}-\mathrm{OA}$ at the same concentration due to the higher dissociation degree of the former than the latter. A high water flux of 62.0 $\mathrm{LMH}$ and an insignificant reverse solute flux of below $0.5 \mathrm{~g} \mathrm{MH}$ were obtained when $1.0 \mathrm{M} \mathrm{Na-Cr-OA}$ as the draw solution and DI water as the feed via a TFC-PES membrane. ${ }^{[50]}$ The impressive performance demonstrates that $\mathrm{Na}-\mathrm{Cr}-\mathrm{OA}$ as a draw solute is superior to those of both the traditional inorganic salts ${ }^{[69]}$ and the previously proposed analogues of hydroacid complexes. ${ }^{[73,80]}$ A high rejection of above $97 \%$ was acquired when a pressure-driven NF process was applied to the recycling of Na-Cr-OA. Although the energy consumption of NF is lower when compared with RO, it is still an energy-intensive process. Therefore, a more energy efficient post-treatment process for the regeneration of hydroacid complexes is crucial to promote their $\mathrm{FO}$ applications in various fields.

In view of the good performance in FO processes, ${ }^{[32,73,80]}$ hydroacid complexes have been employed as draw solutes for a wide range of FO applications recently, such as seawater desalination, ${ }^{[84]}$ heavy metal removal, ${ }^{[29]}$ osmotic power generation, ${ }^{[86]}$ As (III) wastewater treatment, ${ }^{[31]}$ and oily wastewater reclamation. ${ }^{[81]}$ In all these FO applications promoted by hydroacid complexes, high water fluxes and negligible reverse solute fluxes were observed in the FO process. The efficient water recovery in FO demonstrates the practicality of using hydroacid complexes as draw solutes. As aforementioned, hydroacid complexes can be obtained via a simple but efficient one-pot reaction approach. In addition, this type of materials exhibits good water solubility, expanded molecular structures and abundant ionic species in their aqueous solutions. All these features together with the good FO performance make hydroacid complexes attractive as draw solutes for various FO applications.

Based on the above overview, synthetic draw solutes exhibit many advantages in FO processes and are one of the current research focuses of FO technology. The FO performance, applications, regeneration methods, advantages and disadvantages of the aforementioned typical synthetic draw solutes are briefly summarized in Table 1 .

\section{Conclusions and future directions}

Given the advantages of FO processes and the above overview on the progress of FO membrane and draw solute, FO is promising in mitigating the issues caused by freshwater scarcity. However, the existing FO membranes and draw solutes are still confronted with a number of challenges, such as severe $\mathrm{CP}$ and fouling phenomenon, low water permeability, significant reverse solute diffusion, and energy intensive post-treatment, which impede their practical FO applications. ${ }^{[40,52,87]}$ In addition, the current studies on FO focus primarily on the fundamental research of FO technology. Therefore, there is an urgent need to achieve a breakthrough in the advancement of both FO membrane and draw solute for promotion of FO technology from bench scale to practical applications.

For FO membrane, efforts need to be made to reduce membrane fouling and $\mathrm{CP}$ so that better FO performance and lower operation costs can be achieved. In novel FO membrane exploration via membrane modifications, complicated procedures and the involvement of hazardous chemicals which not only increase the membrane fabrication cost but also elevate security requirement should be avoided. The progress of FO membrane can be promoted by not only simplifying the current fabrication procedures but also exploiting more suitable materials and efficient routes for membrane fabrication and modification.

For synthetic draw solutes, the current challenges include mainly: (1) costly starting materials and complicated synthesis procedures; (2) low water permeability; (3) potentially high ICP tendency due to the large sizes in molecular structure; (4) intensive energy consumption in post-treatment and irreproducible FO results generated by the recycled draw solutes; (5) uncertain toxicity. Therefore, future exploration of draw solute should consider the following aspects: (1) cost-effective starting materials, simple and efficient synthetic routes; (2) water flux improved draw solutes by introducing more ionic groups; (3) design of novel draw solute with a reasonable molecular size; (4) both physical and chemical stable materials which can be recycled by a relatively easy way; (5) minimal toxicity.

A novel FO membrane with a thin but robust support layer and a highly selective active layer, and a suitable draw solute carrying plenty of ionic groups and being readily recovered are both essential to promote the development of FO technology and make FO more practical in applications.

\section{Acknowledgement}

We thank the financial supports from the National Natural Science Foundation of China (No. 21677035), the Natural Science Foundation of Fujian Province (No. 2016J01056) and Fuzhou University (No. XRC-1259). 
Table 1 The FO performance, regeneration methods, applications, advantages and disadvantages of some typical synthetic draw solutes

\begin{tabular}{|c|c|c|c|c|c|c|c|}
\hline \multirow[b]{2}{*}{ Draw solutes } & \multicolumn{3}{|l|}{ FO performance } & \multirow{2}{*}{$\begin{array}{l}\text { Regeneration } \\
\text { method }\end{array}$} & \multirow[b]{2}{*}{ Application } & \multirow[b]{2}{*}{ Remarks } & \multirow[b]{2}{*}{ Ref. } \\
\hline & $\begin{array}{l}\text { Feed solution, membrane } \\
\qquad \& \text { operation mode }\end{array}$ & $J_{\mathrm{w}} / \mathrm{LMH}$ & $J_{\mathrm{s}} / \mathrm{gMH}$ & & & & \\
\hline $\begin{array}{c}\text { PEG- }(\mathrm{COOH})_{2} \\
\text { MNPs }\end{array}$ & $\begin{array}{l}\text { DI water, HTI flat sheet } \\
\text { membrane \& PRO mode }\end{array}$ & 13.5 & - & $\begin{array}{l}\text { Magnetic } \\
\text { separator }\end{array}$ & None & $\begin{array}{l}\text { Easy recovery and no draw solute } \\
\text { leakage, particle aggregation } \\
\text { occurrence in regeneration processes }\end{array}$ & [71] \\
\hline CA-MNPs & $\begin{array}{l}\text { DI water, TFC-PES hollow } \\
\text { fiber membrane \& PRO mode }\end{array}$ & $\sim 30.0$ & 0.10 & NF & $\begin{array}{c}\text { Seawater } \\
\text { desalination }\end{array}$ & $\begin{array}{l}\text { High water flux and low reverse } \\
\text { solute flux in FO, intensive energy } \\
\text { consumption in regeneration }\end{array}$ & {$[75]$} \\
\hline PAA-Na & $\begin{array}{l}\text { DI water, CA hollow fiber } \\
\text { membrane \& PRO mode }\end{array}$ & $\sim 22.0$ & $<0.18$ & UF & $\begin{array}{c}\text { Seawater } \\
\text { desalination }\end{array}$ & $\begin{array}{l}\text { Easy synthesis, high water flux in } \\
\text { FO, high viscosity }\end{array}$ & {$[72]$} \\
\hline PAA-Na & $\begin{array}{l}50 \text { ppm acid orange } 8, \\
\text { CA hollow fiber membrane } \\
\& \text { PRO mode }\end{array}$ & $\sim 30.0$ & $<0.14$ & MD & $\begin{array}{c}\text { Dye wastewater } \\
\text { treatment }\end{array}$ & $\begin{array}{l}\text { Easy synthesis, high water flux in } \\
\text { FO, high viscosity }\end{array}$ & [79] \\
\hline $\mathrm{Na}-\mathrm{Fe}-\mathrm{CA}$ & $\begin{array}{l}\text { DI water, CA hollow fiber } \\
\text { membrane \& PRO mode }\end{array}$ & 43.0 & $\sim 0.1$ & NF & - & $\begin{array}{l}\text { Easy synthesis, high water flux in } \\
\text { FO, intensive energy consumption } \\
\text { in regeneration }\end{array}$ & {$[73]$} \\
\hline $\mathrm{Na}-\mathrm{Fe}-\mathrm{CA}$ & $\begin{array}{l}\text { DI water, TFC-matrimid hollow } \\
\text { fiber membrane \& PRO mode }\end{array}$ & 62.1 & 0.4 & precipitation & $\begin{array}{c}\text { Power } \\
\text { generation }\end{array}$ & $\begin{array}{l}\text { High power generation efficiency in } \\
\text { FO, large amount of organic solvent } \\
\text { required in draw solutes recovery }\end{array}$ & {$[86]$} \\
\hline $\mathrm{Na}-\mathrm{Co}-\mathrm{CA}$ & $\begin{array}{l}3.5 \mathrm{wt} \% \mathrm{NaCl}, \mathrm{TFC}-\mathrm{PES} \text { hollow } \\
\text { fiber membrane \& PRO mode }\end{array}$ & 13.0 & $\begin{array}{l}\text { Negligi- } \\
\text { ble }\end{array}$ & NF & $\begin{array}{c}\text { Seawater } \\
\text { desalination }\end{array}$ & $\begin{array}{l}\text { High water flux and negligible } \\
\text { reverse solute flux in FO, intensive } \\
\text { energy consumption in regeneration }\end{array}$ & {$[80]$} \\
\hline $\mathrm{Na}-\mathrm{Co}-\mathrm{CA}$ & $\begin{array}{l}5000 \text { ppm heavy metal solution, } \\
\text { TFC-matrimid membrane \& FO } \\
\text { mode }\end{array}$ & 10.5 & $\begin{array}{c}0.92 \pm 0.0 \\
6\end{array}$ & - & $\begin{array}{l}\text { Heavy metal } \\
\text { removal }\end{array}$ & $\begin{array}{l}\text { High heavy metal removal } \\
\text { efficiency, no draw solutes } \\
\text { regeneration process }\end{array}$ & [29] \\
\hline $\mathrm{Na}-\mathrm{Cr}-\mathrm{OA}$ & $\begin{array}{l}\text { DI water, TFC-PES hollow fiber } \\
\text { membrane \& PRO mode }\end{array}$ & 62.0 & $<0.5$ & NF & $\begin{array}{c}\text { Protein } \\
\text { enrichment }\end{array}$ & $\begin{array}{l}\text { High water flux and negligible } \\
\text { reverse solute flux in FO, intensive } \\
\text { energy consumption in draw } \\
\text { solutes regeneration }\end{array}$ & {$[32]$} \\
\hline $\mathrm{Na}-\mathrm{Cr}-\mathrm{OA}$ & $\begin{array}{l}1000 \text { ppm As(III) solution, } \\
\text { TFC-PES hollow fiber } \\
\text { membrane \& PRO mode }\end{array}$ & 74.0 & $<0.4$ & MD & $\begin{array}{l}\text { As(III) } \\
\text { removal }\end{array}$ & $\begin{array}{l}\text { High water flux in FO, intensive } \\
\text { energy consumption in draw } \\
\text { solutes regeneration }\end{array}$ & {$[31]$} \\
\hline NH4-Cr-OA & $\begin{array}{l}3000 \text { ppm petroleum-water } \\
\text { TFC-PES hollow fiber } \\
\text { membrane \& PRO mode }\end{array}$ & $\sim 90.00$ & $<0.8$ & MD & $\begin{array}{l}\text { Oily wastewater } \\
\text { treatment }\end{array}$ & $\begin{array}{l}\text { High water flux in FO, intensive } \\
\text { energy consumption in draw } \\
\text { solutes regeneration }\end{array}$ & {$[81]$} \\
\hline
\end{tabular}




\section{References}

[1] Arnell, N. W. Global Environ. Chang. 1999, 9, 31

[2] Cosgrove, W. J.; Loucks, D. P. Water Resour. Res. 2015, 51, 4823.

[3] McGinnis, R. L.; Elimelech, M. Environ. Sci. Technol. 2008, 42, 8625.

[4] Akther, N.; Sodiq, A.; Giwa, A.; Daer, S.; Arafat, H. A.; Hasan, S. W. Chem. Eng. J. 2015, 281, 502 .

[5] Jacangelo, J. G.; Trussell, R. R.; Watson, M. Desalination 1997, 113, 119.

[6] Wilas, J.; Draszawka-Bołzan, B.; Daniszewski, P.; Cyraniak, E. Wnofns 2016, 4, 33.

[7] Muga, H. E.; Mihelcic, J. R. J. Environ. Manage. 2008, 88, 437.

[8] Lutchmiah, K.; Verliefde, A. R. D.; Roest, K.; Rietveld, L. C.; Cornelissen, E. R. Water Res. 2014, 58, 179.

[9] Rodriguez-Narvaez, O. M.; Peralta-Hernandez, J. M.; Goonetilleke, A.; Bandala, E. R. Chem. Eng. J. 2017, 323, 361.

[10] Cath, T. Y.; Childress, A. E.; Elimelech, M. J. Membr. Sci. 2006, 281, 70.

[11] Li, D.; Yan, Y.; Wang, H. Prog. Polym. Sci. 2016, 61, 104.

[12] Neoh, C. H.; Noor, Z. Z.; Mutamin, N. S. A.; Lim, C. K. Chem. Eng. J. 2016, 283,582 .

[13] Song, L. J. Membr. Sci. 1998, 139, 183.

[14] Cui, J.; Zhang, X.; Liu, H.; Liu, S.; Yeung, K. L. J. Membr. Sci. 2008, 325,420 .

[15] Rayess, Y. E.; Albasi, C.; Bacchin, P.; Taillandier, P.; Raynal, J. Mietton-Peuchot, M.; Devatine, A. J. Membr. Sci. 2011, 382, 1.

[16] Islam, M. S.; McCutcheon, J. R.; Rahaman, M. S. J. Membr. Sci. 2017, $537,297$.

[17] Gao, W.; Liang, H.; Ma, J.; Han, M.; Chen, Z. L.; Han, Z. S.; Li, G. B. Desalination 2011, 272, 1 .

[18] Sheng, C.; Nnanna, A.G. A.; Liu, Y.; Vargo, J. D. Sci. Total Environ. 2016, 550, 1075 .

[19] Hilala, N.; A1-ZoubP, H.; Darwishb, N. A.; Mohammad, A. W.; Arabi, M. A. Desalination 2004, 170, 281

[20] Radjenovic', J.; Petrovic', M.; Ventura, F.; Barcelo, D. Water Res. 2008, $42,3601$.

[21] Xu, Y. C.; Tang, Y. P.; Liu, L. F.; Guo, Z. H.; Shao, L. J. Membr. Sci. 2017, 526, 32.

[22] Fritzmann, C.; Löwenberg, J.; Wintgens, T.; Melin, T. Desalination 2007, 216,1

[23] Soltanieh, M.; Gill, W. N. Chem. Eng. Commun. 1981, 12. 279.

[24] Choi, Y. J. ; Choi, J. S.; Oh, H. J. ; Lee, S.; Yang, D. R. ; Kim, J. H.; Desalination 2009, 247, 239

[25] Westerhoff, P.; Moon, H.; Minakata, D.; Crittenden, J. Water Res. 2009, 43, 3992

[26] Lee, K. P.; Arnot, T. C.; Mattia, D. J. Membr. Sci. 2011, 370, 1

[27] She, Q.; Wang, R.; Fane, A. G.; Tang, C. Y. J. Membr. Sci. 2016, 499, 201.

[28] McCutcheon, J. R.; McGinnis, R. L.; Elimelech, M. J. Membr. Sci. 2006, 278,114

[29] Cui, Y.; Ge, Q.; Liu, X. Y.; Chung, T. S. J. Membr. Sci. 2014, 467, 188

[30] Nasr, P.; Sewilam, H. Clean Technol. Environ. 2015, 17, 2079.

[31] Ge, Q.; Han, G.; Chung, T. S. Environ. Sci. Technol. 2016, 50, 2363.

[32] Ge, Q.; Chung, T. S. Chem. Commun. 2015, 51, 4854.

[33] Ling, M. M.; Chung, T. S. J. Membr. Sci. 2011, 372, 201

[34] Kim, Y. C.; Elimelech, M. J. Membr. Sci. 2013, 429, 330.

[35] Klaysom, C.; Cath, T. Y.; Depuydt, T.; Vankelecom, I. F. J. Chem. Soc. Rev. 2013, 42, 6959.

[36] Guo, C. X.; Huang, S.; Lu, X. Green Chem. 2014, 16, 2571.

[37] Chung, T. S.; Li, X.; Ong, R. C.; Ge, Q.; Wang, H.; Han, G. Curr. Opin. Chem. Eng. 2012, 1, 246

[38] Chung, T. S.; Zhang, S.; Wang, K. Y.; Su, J.; Ling, M. M. Desalination 2012, 287, 78 .

[39] Zhao, S.; Zou, L.; Tang, C. Y.; Mulcahy, D. J. Membr. Sci. 2012, 396, 1.

[40] Ge, Q.; Ling, M. M.; Chung, T. S. J. Membr. Sci. 2013, 442, 225

[41] Van der Bruggen, B.; Luis, P. Rev. Chem. Eng. 2015, 31, 1.

[42] Lu, X.; Boo, C.; Ma, J.; Elimelech, M. Environ. Sci. Technol. 2014, 48 , 14369

[43] Tang, C. Y.; She, Q.; Lay, W. C. L.; Wang, R.; Fane, A. G. J. Membr Sci. 2010, 354, 123
[44] Yip, N. Y.; Tiraferri, A.; Phillip, W. A.; Schiffman, J. D.; Elimelech, M. Environ. Sci. Technol. 2010, 44, 3812.

[45] https://en.wikipedia.org/wiki/Osmitic pressure.

[46] Amiji, M. M.; Beverly, J. S. Applied Physical Pharmacy, McGraw-Hill Medical, 2002.

[47] McCutcheon, J. R.; McGinnis, R. L.; Elimelech, M. Desalination 2005 174,1

[48] Kravath, R. E.; Davis, J. A. Desalination, 1975, 16, 151.

[49] Wang, K. Y.; Chung, T. S.; Qin, J. J. J. Membr. Sci. 2007, 300, 6.

[50] Sukitpaneenit, P.; Chung, T. S. Environ. Sci. Technol. 2012, 46, 7358.

[51] Ghosh, A. K.; Hoek, E. M. V. J. Membr. Sci. 2009, 336, 140.

[52] Xu, W.; Chen, Q.; Ge, Q. Desalination, 2017, 419, 101

[53] Rana, D.; Matsuura, T. Chem. Rev. 2010, 110, 2448.

[54] Emadzadeh, D.; Lau, W. J.; Matsuura, T.; Rahbari-Sisakht, M.; Ismail, A. F. Chem. Eng. J. 2014, 237, 70

[55] Huang, M.; Chen, Y.; Huang, C. H.; Sun, P.; Crittenden, J. Chem. Eng. J. 2015, 279, 904

[56] Ma, N.; Wei, J.; Liao, R.; Tang, C. Y. J. Membr. Sci. 2012, 405-406, 149.

[57] Yu, H. Y.; Kang, Y.; Liu, Y.; Mi, B. J. Membr. Sci. 2014, 449, 50.

[58] Lu, X.; Castrillón, S. R. V.; Shaffer, D. L.; Ma, J.; Elimelech, M. Environ. Sci. Technol. 2013, 47, 12219.

[59] Wang, Y.; Li, X.; Cheng, C.; He, Y.; Pan, J.; Xu, T. J. Membr. Sci. 2016, 498, 30 .

[60] Shaffer, D. L.; Jaramillo, H.; Castrillón, S. R. V. Lu, X.; Elimelech, M. J. Membr. Sci. 2015, 490, 209.

[61] Cho, Y. H.; Han, J.; Han, S.; Guiver, M. D.; Park, H. B. J. Membr. Sci. 2013, 445, 220 .

[62] Zhong, P.; Fu, X.; Chung, T. S.; Weber, M.; Maletzko, C. Environ. Sci. Technol. 2013, 47, 7430.

[63] Duong, P. H. H.; Chisca, S.; Hong, P. Y.; Cheng, H.; Nunes, S. P.; Chung, T. S. ACS Appl. Mater. Inter. 2015, 7, 3960.

[64] Wang, K.; Chung, T. S. AIChE J. 2012, 58, 770.

[65] Widjojo, N.; Chung, T. S.; Weber, M.; Maletzko, C.; Warzelhan, V. J. Membr. Sci. 2011, 383, 214.

[66] Chekli, L.; Phuntsho, S.; Shon, H. K.; Vigneswaran, S.; Kandasamy, J.; Chanan, A. Desalin. Water Treat. 2012, 43, 167

[67] Li, D.; Wang, H. J. Mater. Chem. A 2013, $1,14049$.

[68] Zhao, D.; Chen, S.; Guo, C. X.; Zhao, Q.; Lu, X. Chin. J. Chem. Eng. 2016, 24, 23.

[69] Achilli, A.; Cath, T. Y.; Childress, A. E. J. Membr. Sci. 2010, 364, 233.

[70] Wei, J.; Qiu, C.; Tang, C. Y.; Wang, R.; Fane, A. G. J. Membr. Sci. 2011 , $372,292$.

[71] Ge, Q.; Su, J.; Chung, T. S.; Amy, G. Ind. Eng. Chem. Res. 2011, 50, 382.

[72] Ge, Q.; Su, J.; Amy, G. L.; Chung, T. S. Water Res. 2012, 46, 1318.

[73] Ge, Q.; Chung, T. S. Chem. Commun. 2013, 49, 8471 .

[74] Bai, H.; Liu, Z.; Sun, D. D. Sep. Purif. Technol. 2011, 81, 392.

[75] Ge, Q.; Yang, L.; Cai, J.; Xu, W.; Chen, Q.; Liu, M. J. Membr. Sci. 2016, 520,550 .

[76] Ling, M. M.; Wang, K. Y.; Chung, T. S. Ind. Eng. Chem. Res. 2010, 49, 5869

[77] Dey, P.; Izake, E. L. Desalination 2015, 373, 79.

[78] Zhang, M.; She, Q.; Yan, X.; Tang, C. Y. Desalination 2017, 401, 230.

[79] Ge, Q.; Wang, P.; Wan, C.; Chung, T. S. Environ. Sci. Technol. 2012, 46, 6236.

[80] Ge, Q.; Fu, F.; Chung, T. S. Water Res. 2014, 58, 230.

[81] Ge, Q.; Amy, G. L.; Chung, T. S. Water Res. 2017, 122, 580.

[82] Zhao, D.; Chen, S.; Wang, P.; Zhao, Q.; Lu, X. Ind. Eng. Chem. Res 2014, 53, 16170

[83] Zhou, A.; Luo, H.; Wang, Q.; Chen, L.; Zhang, T. C.; Tao, T. RCS Adv 2015, 5, 15359 .

[84] Wang, P.; Cui, Y.; Ge, Q.; Tew, T. F.; Chung, T. S. J. Membr. Sci. 2015, 494,1 .

[85] Su, J.; Chung, T. S. J. Membr. Sci. 2011, 376, 214

[86] Han, G.; Ge, Q.; Chung, T.S. Appl. Energ. 2014, 132, 383.

[87] Chung, T. S.; Luo, L.; Wan, C. F.; Cui, Y.; Amy, G. Sep. Purif. Technol. 2015, 156,856 